\title{
INFLUENCE OF THE TEMPERATURE AND TYPE OF SALT ON THE PHASE EQUILIBRIUM OF PEG $1500+$ POTASSIUM PHOSPHATE AND PEG 1500 + SODIUM CITRATE AQUEOUS TWO-PHASE SYSTEMS
}

\author{
Carolina P. Carvalho, Jane Sélia R. Coimbra*, Isabele Andressa F. Costa, Luis Antonio Minim and Maria Cristina \\ Maffia \\ Departamento de Tecnologia de Alimentos, Universidade Federal de Viçosa, Av. P. H. Rolfs, s/n, 36570-000 Viçosa - MG, Brazil \\ Luis Henrique M. Silva \\ Departamento de Química, Universidade Federal de Viçosa, Av. P. H. Rolfs, s/n, 36570-000 Viçosa - MG, Brazil
}

Recebido em 6/10/06; aceito em 24/8/07; publicado na web em 19/12/07

\begin{abstract}
The present work analyzed the effect of the temperature and type of salt on the phase equilibrium of aqueous two-phase systems (ATPS) formed by poly (ethylene glycol) (PEG) 1500 + potassium phosphate, from (278.15 to 318.15) K, and PEG 1500 + sodium citrate, from (278.15 to 298.15) K. The rise of the temperature normally increased the slope of the tie line (STL). With respect to the influence of the type of salt, sodium citrate showed better capability to induce phase separation, when compared to potassium phosphate.
\end{abstract}

Keywords: aqueous two-phase systems; equilibrium data; salts.

\section{INTRODUCTION}

In 1896, Beijerinck observed that when aqueous solutions of starch and jelly (or agar-agar and jelly) were mixed, a system composed by two liquid phases was formed, with an inferior phase rich in starch (or agar-agar) and a superior phase rich in jelly. Further studies performed by Ostwald and Hertel showed that various types of starch, at different concentrations, should be mixed for the occurrence of phase separation. In 1947, Dobry and Boyer-Kawenoki tested numerous polymers pairs and observed phase separation in most of them ${ }^{1}$.

Albertsson, in 1958, proposed the application of aqueous twophase systems (ATPS) for bioseparation purposes. He used aqueous systems constituted by poly (ethylene glycol) (PEG) and dextran to successfully separate various biomolecules ${ }^{2}$.

Ever since, several studies have been performed, which expand the use of ATPS for the partition of animal and plant cells, chloroplasts, enzymes, metals, mitochondrias, mushrooms and their spores, nucleic acids and proteins ${ }^{3-10}$.

ATPS are suitable for the separation of biomaterials, due to their low interfacial tension and elevated water content that preserve the natural activity of labile constituents. Polymer + salt ATPS are particularly useful, since they present relatively low cost and low viscosity, which provide an efficient phase separation ${ }^{11-16}$.

Equilibrium data for aqueous systems formed by PEG + sodium citrate and particularly for those composed of PEG + potassium phosphate are quite available ${ }^{17-28}$. However, there is nowadays a considerable demand for comprehensive studies with reference to the effect of operational conditions on the behavior of ATPS ${ }^{29}$. Nevertheless, such studies are relatively restricted, which makes difficult the scale-up of bioseparation processes that apply these systems. Additionally, comparative studies between ATPS with potassium phosphate and sodium citrate are very scarce.

In view of that, this work aims to expand and facilitate the application of ATPS in the chemical and biochemical industries, by the measurement and the analysis of the effect of the temperature and type of salt on the phase equilibrium of aqueous systems constituted by PEG 1500 + potassium phosphate, from (278.15 to

*e-mail: jcoimbra@ufv.br
318.15) K, and PEG 1500 + sodium citrate, from (278.15 to 298.15) $\mathrm{K}$. These data are necessary for the optimization of industrial processes that use liquid-liquid extraction.

\section{EXPERIMENTAL}

\section{Materials}

PEG ( $M=1500 \mathrm{~g} \mathrm{~mol}^{-1}$, Isofar, Brazil), potassium phosphate and sodium citrate (Vetec, Brazil), with purities superior than $99 \%$, were used.

\section{Experimental procedure}

ATPS were prepared by the addition of appropriate quantities of water, salt and stock solution of PEG ( 0.50 mass fraction) into a centrifuge tube, to obtain $40 \mathrm{~g}$ of mixture. The water used to make each system was previously distilled and deionized with a Millipore (USA) apparatus. The $\mathrm{pH}$ of the mixtures formed by potassium phosphate was adjusted to 7 by the addition of mono and dibasic potassium phosphate in the proportion of $1: 1.82$, respectively, and was monitored with \pm 0.01 by a DM-20 pH meter (Digimed, Brazil). The $\mathrm{pH}$ of the mixtures composed of sodium citrate was close to 7 and required no adjustment.

Each mixture was further centrifuged at $2000 \mathrm{~g}$ for $20 \mathrm{~min}$ with an Eppendörf (Germany) device and transferred to an equilibrium cell, where the mixture was allowed to settle for $24 \mathrm{~h}$, at the operational temperature $((278.15$ to 318.15$) \mathrm{K}$ for the systems constituted by potassium phosphate and (278.15 to 298.15$) \mathrm{K}$ for the systems formed by sodium citrate), to obtain clear phase separation and to reach the equilibrium. The temperature was monitored with $\pm 0.01 \mathrm{~K}$ by a thermostatic water bath (Tecnal, Brazil). Each resultant phase was carefully collected and its density was measured with a pycnometer $(10 \mathrm{~mL})$, previously calibrated with water at the operational temperature. The amount of salt was experimentally determined by flame photometry with a Celm (Brazil) apparatus. The quantity of water was quantified by freeze drying with an Edwards (Brazil) device. The sample was previously weighed with $\pm 0.0001 \mathrm{~g}$ accuracy by a Denver (USA) analytical balance and 
subsequently frozen. The amount of water was obtained from the variation of the sample weight before and after the drying process, equivalent to the mass of water evaporated. The quantity of PEG was determined from the difference between the mass of the dried sample and the amount of the salt, as shown by Equation 1:

$m_{\mathrm{PEG}}=m_{\mathrm{DS}}-m_{\mathrm{S}}$

where $m_{\mathrm{PEG}}, m_{\mathrm{DS}}$ and $m_{\mathrm{S}}$ are the masses (g) of PEG, dried sample and salt, respectively. All measurements were made in triplicate.

\section{RESULTS AND DISCUSSION}

Tables 1 to 2 and Figures 1 to 2 present liquid-liquid equilibrium data for ATPS composed by PEG $1500+$ potassium phosphate, from
(278.15 to 318.15$) \mathrm{K}$, and PEG 1500 + sodium citrate, from (278.15 to 298.15) K. It was found five tie lines for each temperature studied. PEG, salt and water quantities are expressed as mass fractions $(w)$. Measurement uncertainties were statistically analyzed by the estimation of the resultant mean standard deviation, with values equal to \pm 0.0020 and \pm 0.0140 , for salt and water measurements, respectively. The amount of PEG was obtained by Equation 1, as previously explained.

The effect of the temperature on phase equilibrium was studied by the application of the slope of the tie line (STL) concept. This value is computed as the ratio between the variation of the polymer and salt concentration in each phase of the system (Equation 2). Tables 3 and 4 show the values of the STL found for PEG + potassium phosphate ATPS, from (278.15 to 318.15$) \mathrm{K}$, and PEG + sodium citrate ATPS, from (278.15 to 298.15) K.

Table 1. Liquid-liquid equilibrium data for PEG 1500 + potassium phosphate + water systems from (278.15 to 318.15$) \mathrm{K}$

\begin{tabular}{|c|c|c|c|c|c|c|c|c|c|}
\hline \multirow[t]{2}{*}{ Tie Line } & \multicolumn{3}{|c|}{ Overall } & \multicolumn{3}{|c|}{ Top Phase } & \multicolumn{3}{|c|}{ Bottom Phase } \\
\hline & $w_{\mathrm{PEG}}$ & $w_{\mathrm{S}}$ & $w_{\mathrm{W}}$ & $w_{\mathrm{PEG}}$ & $w_{\mathrm{s}}$ & $w_{\mathrm{W}}$ & $w_{\mathrm{PEG}}$ & $w_{\mathrm{s}}$ & $w_{\mathrm{W}}$ \\
\hline \multicolumn{10}{|c|}{$278.15 \mathrm{~K}$} \\
\hline 1 & 0.1585 & 0.1060 & 0.7355 & 0.2413 & 0.0623 & 0.6964 & 0.0467 & 0.1959 & 0.7574 \\
\hline 2 & 0.1711 & 0.1207 & 0.7082 & 0.2946 & 0.0457 & 0.6597 & 0.0796 & 0.2321 & 0.6882 \\
\hline 3 & 0.1786 & 0.1319 & 0.6895 & 0.3237 & 0.0388 & 0.6375 & 0.0878 & 0.2376 & 0.6746 \\
\hline 4 & 0.1960 & 0.1485 & 0.6555 & 0.3717 & 0.0299 & 0.5984 & 0.0699 & 0.2761 & 0.6539 \\
\hline 5 & 0.2084 & 0.1639 & 0.6277 & 0.4109 & 0.0199 & 0.5692 & 0.0210 & 0.3268 & 0.6522 \\
\hline \multicolumn{10}{|c|}{ 298.15 K } \\
\hline 1 & 0.1502 & 0.0995 & 0.7503 & 0.2137 & 0.0682 & 0.7181 & 0.0705 & 0.1643 & 0.7652 \\
\hline 2 & 0.1597 & 0.1127 & 0.7276 & 0.2778 & 0.0499 & 0.6723 & 0.0534 & 0.2071 & 0.7395 \\
\hline 3 & 0.1696 & 0.1197 & 0.7107 & 0.3113 & 0.0450 & 0.6438 & 0.0563 & 0.2165 & 0.7272 \\
\hline 4 & 0.1796 & 0.1301 & 0.6903 & 0.3451 & 0.0368 & 0.6181 & 0.0378 & 0.2465 & 0.7157 \\
\hline 5 & 0.1932 & 0.1400 & 0.6668 & 0.3813 & 0.0323 & 0.5864 & 0.1276 & 0.2733 & 0.5991 \\
\hline \multicolumn{10}{|c|}{$308.15 \mathrm{~K}$} \\
\hline 1 & 0.1449 & 0.1114 & 0.7437 & 0.2341 & 0.0622 & 0.7038 & 0.0396 & 0.1836 & 0.7769 \\
\hline 2 & 0.1582 & 0.1065 & 0.7353 & 0.2509 & 0.0583 & 0.6908 & 0.0471 & 0.1786 & 0.7743 \\
\hline 3 & 0.1665 & 0.1166 & 0.7169 & 0.3083 & 0.0475 & 0.6442 & 0.0288 & 0.2110 & 0.7602 \\
\hline 4 & 0.1733 & 0.1251 & 0.7016 & 0.3530 & 0.0400 & 0.6071 & 0.0483 & 0.2319 & 0.7198 \\
\hline 5 & 0.1868 & 0.1287 & 0.6845 & 0.3676 & 0.0342 & 0.5982 & 0.0599 & 0.2647 & 0.6754 \\
\hline \multicolumn{10}{|c|}{ 318.15 K } \\
\hline 1 & 0.1544 & 0.1070 & 0.7386 & 0.3077 & 0.0421 & 0.6502 & 0.0161 & 0.2242 & 0.7597 \\
\hline 2 & 0.1632 & 0.1152 & 0.7216 & 0.2460 & 0.0359 & 0.7180 & 0.1176 & 0.2424 & 0.6400 \\
\hline 3 & 0.1755 & 0.1250 & 0.6994 & 0.4917 & 0.0317 & 0.4766 & 0.0596 & 0.2522 & 0.6882 \\
\hline 4 & 0.1869 & 0.1371 & 0.6760 & 0.4856 & 0.0272 & 0.4872 & 0.0022 & 0.2845 & 0.7132 \\
\hline 5 & 0.1967 & 0.1612 & 0.6421 & 0.4702 & 0.0299 & 0.4999 & 0.0068 & 0.2663 & 0.7269 \\
\hline
\end{tabular}

Table 2. Liquid-liquid equilibrium data for PEG 1500 + sodium citrate + water systems from (278.15 to 298.15) K

\begin{tabular}{|c|c|c|c|c|c|c|c|c|c|}
\hline \multirow[t]{2}{*}{ Tie Line } & \multicolumn{3}{|c|}{ Overall } & \multicolumn{3}{|c|}{ Top Phase } & \multicolumn{3}{|c|}{ Bottom Phase } \\
\hline & $w_{\mathrm{PEG}}$ & $w_{\mathrm{s}}$ & $w_{\mathrm{W}}$ & $w_{\mathrm{PEG}}$ & $w_{\mathrm{s}}$ & $w_{\mathrm{W}}$ & $w_{\mathrm{PEG}}$ & $w_{\mathrm{S}}$ & $w_{\mathrm{W}}$ \\
\hline \multicolumn{10}{|c|}{$278.15 \mathrm{~K}$} \\
\hline 1 & 0.1834 & 0.1068 & 0.7098 & 0.3056 & 0.0548 & 0.6396 & 0.1319 & 0.1773 & 0.6908 \\
\hline 2 & 0.2040 & 0.1157 & 0.6803 & 0.3504 & 0.0453 & 0.6043 & 0.1216 & 0.2228 & 0.6556 \\
\hline 3 & 0.2245 & 0.1255 & 0.6500 & 0.4059 & 0.0291 & 0.5650 & 0.1270 & 0.2572 & 0.6158 \\
\hline 4 & 0.2452 & 0.1345 & 0.6203 & 0.4231 & 0.0192 & 0.5577 & 0.1411 & 0.2726 & 0.5863 \\
\hline 5 & 0.2626 & 0.1417 & 0.5957 & 0.4492 & 0.0190 & 0.5318 & 0.1369 & 0.2927 & 0.5704 \\
\hline \multicolumn{10}{|c|}{$298.15 \mathrm{~K}$} \\
\hline 1 & 0.1832 & 0.1201 & 0.6967 & 0.1902 & 0.0573 & 0.7525 & 0.0380 & 0.2076 & 0.7544 \\
\hline 2 & 0.2024 & 0.1299 & 0.6677 & 0.2769 & 0.0386 & 0.6845 & 0.0892 & 0.2511 & 0.6597 \\
\hline 3 & 0.2226 & 0.1401 & 0.6373 & 0.2813 & 0.0332 & 0.6855 & 0.1030 & 0.2641 & 0.6329 \\
\hline 4 & 0.2425 & 0.1497 & 0.6078 & 0.3341 & 0.0242 & 0.6417 & 0.1062 & 0.2811 & 0.6127 \\
\hline 5 & 0.2634 & 0.1602 & 0.5764 & 0.3923 & 0.0218 & 0.5859 & 0.0994 & 0.2929 & 0.6077 \\
\hline
\end{tabular}



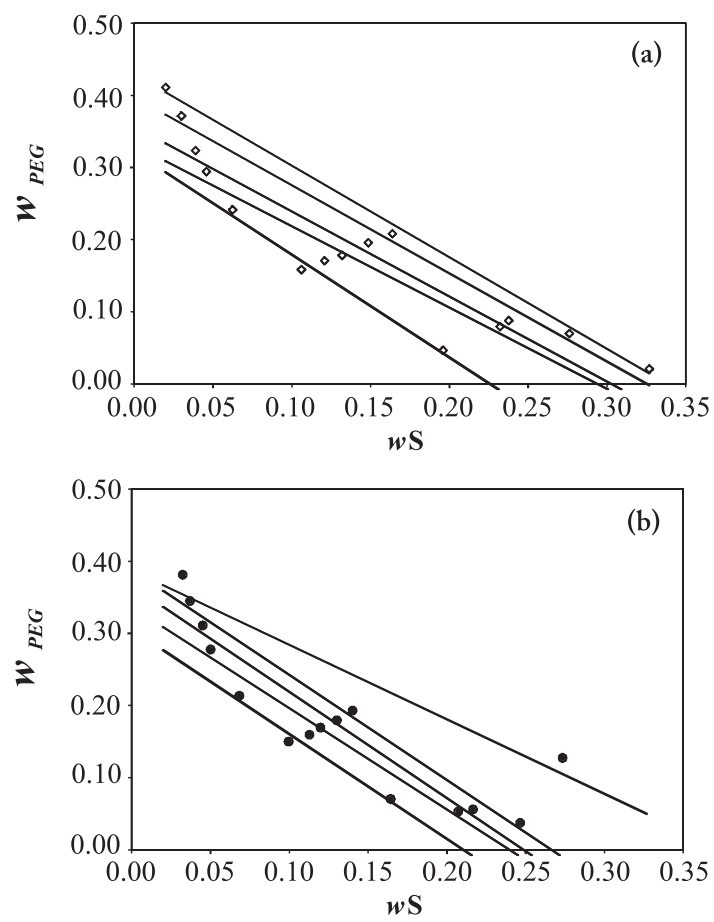

Figure 1. Liquid-liquid equilibrium data for PEG $1500+$ potassium phosphate + water systems at $(\diamond) 298.15 \mathrm{~K}(\boldsymbol{a})$ and $(\bullet) 308.15 \mathrm{~K}(\boldsymbol{b})$; (一) tie line

$\mathrm{STL}=\frac{C_{\mathrm{P}}^{\mathrm{T}}-C_{\mathrm{P}}^{\mathrm{B}}}{C_{\mathrm{S}}^{\mathrm{T}}-C_{\mathrm{S}}^{\mathrm{B}}}$

where $C_{\mathrm{p}}$ and $C_{\mathrm{s}}$ are the polymer and salt concentrations $\left(\mathrm{g} \mathrm{cm}^{-3}\right)$, and the superscripts $\mathrm{T}$ and $\mathrm{B}$ refer to the top and bottom phases, respectively.

Table 3. STL values for PEG $1500+$ potassium phosphate + water systems

\begin{tabular}{lllll}
\hline Tie Line & \multicolumn{4}{c}{$T / \mathrm{K}$} \\
& $\mathbf{2 7 8 . 1 5}$ & $\mathbf{2 9 8 . 1 5}$ & $\mathbf{3 0 8 . 1 5}$ & $\mathbf{3 1 8 . 1 5}$ \\
\hline 1 & 0.0175 & 0.0179 & 0.0176 & 0.0167 \\
2 & 0.0160 & 0.0174 & 0.0185 & 0.0167 \\
3 & 0.0159 & 0.0177 & 0.0176 & 0.0173 \\
4 & 0.0149 & 0.0164 & 0.0173 & 0.0163 \\
5 & 0.0136 & 0.0155 & 0.0167 & 0.0167 \\
\hline
\end{tabular}

Table 4. STL values for PEG $1500+$ sodium citrate + water systems

\begin{tabular}{lll}
\hline Tie Line & \multicolumn{3}{c}{$T / \mathrm{K}$} & $\mathbf{2 9 8 . 1 5}$ \\
\hline 1 & 1.6020 & 1.6430 \\
2 & 1.4670 & 1.5510 \\
3 & 1.3780 & 1.5270 \\
4 & 1.3800 & 1.4840 \\
5 & 1.3550 & 1.4640 \\
\hline
\end{tabular}

The STL normally increased with the rise of temperature. For PEG 1500 + potassium phosphate ATPS, an increase of 9.0 and $3.4 \%$ between (278.15 and 298.15) $\mathrm{K}$ and (298.15 and 308.15) K, respectively, was found. However, a decrease of $4.5 \%$ was observed between (308.15 and 318.15) K.

Carvalho et al. ${ }^{28}$ analyzed the influence of the temperature on the behavior of PEG 4000 + potassium phosphate ATPS, from
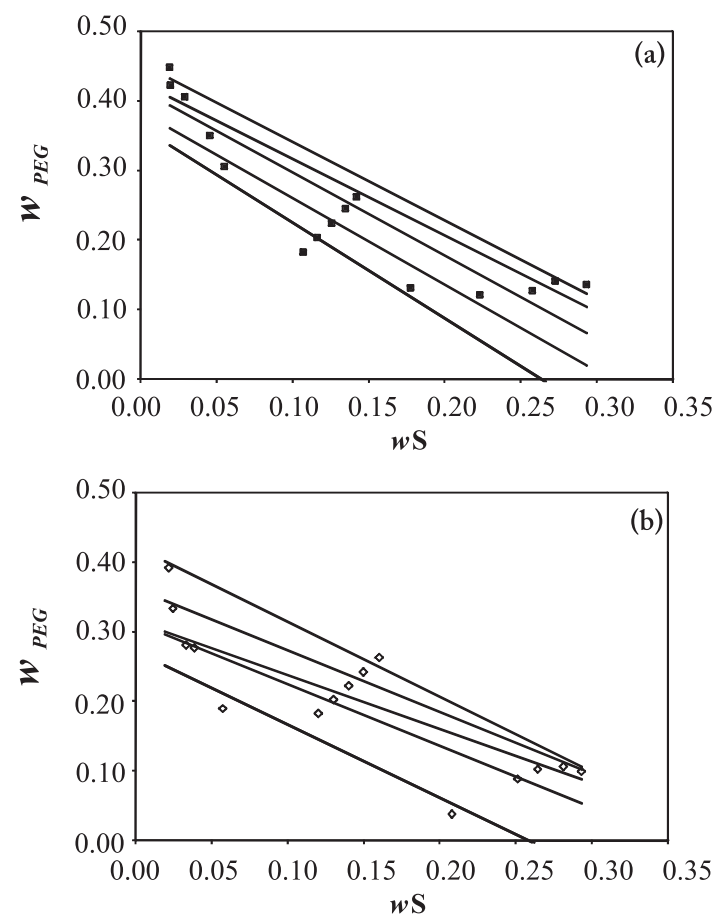

Figure 2. Liquid-liquid equilibrium data for PEG 1500 + sodium citrate + water systems at $(\square) 278.15 \mathrm{~K}(\boldsymbol{a})$ and $(\diamond) 298.15 \mathrm{~K}(\boldsymbol{b})$; (一) tie line

(278.15 to 318.15$) \mathrm{K}$, and verified that the increase of the STL became less pronounced with the rise of temperature, with values of $14.0,10.0$ and $6.8 \%$ between $(278.15$ and 298.15$) \mathrm{K}$, (298.15 to $308.15) \mathrm{K}$ and (308.15 to 318.15$) \mathrm{K}$, respectively (Table 5).

Table 5. STL values for PEG $4000+$ potassium phosphate + water systems*

\begin{tabular}{lllll}
\hline Tie Line & \multicolumn{3}{c}{$T / \mathrm{K}$} \\
& $\mathbf{2 7 8 . 1 5}$ & $\mathbf{2 9 8 . 1 5}$ & $\mathbf{3 0 8 . 1 5}$ & $\mathbf{3 1 8 . 1 5}$ \\
\hline 1 & 0.0175 & 0.0204 & 0.0206 & 0.0235 \\
2 & 0.0165 & 0.0185 & 0.0202 & 0.0225 \\
3 & 0.0148 & 0.0174 & 0.0194 & 0.0199 \\
4 & 0.0152 & 0.0161 & 0.0187 & 0.0190 \\
5 & 0.0134 & 0.0157 & 0.0178 & 0.0185 \\
\hline "Carvalho et al. ${ }^{\mathbf{2 8}}$ & & &
\end{tabular}

For all aqueous systems formed by PEG 1500 + sodium citrate the rise of the temperature, from (278.15 to 298.15$) \mathrm{K}$, led to an increase of the STL.

The STL values are resulting from interactions between all ATPS forming components, which promote the partitioning of each of them between the phases in order to minimize the free energy of the systems. The temperature dependence of the STL reflects the kinetic and potential energy balance $\left(\Delta U(\mathrm{~K} T)^{-1}\right)$ existent in each pair ${ }^{30}$. If the intermolecular interaction $(\Delta U)$ is of the same magnitude of $\mathrm{KT}$, the increase of temperature might result on the break of a specific interaction. Using a calorimetric technique, Silva and $\mathrm{Loh}^{31}$ measured enthalpies of transfer $\left(\Delta H_{\mathrm{TR}}\right)$ for some salts from water and poly (ethylene glycol) (PEG) systems. It was observed that such electrolyte transferring process is ever endothermic, indicating that any occurring salt + polymer interaction should be followed by an increase in the system entropy, which drives the interaction process. The increase of the entropy system has been ascribed to the release of water molecules that were involved in ion and polymer solvation. 
Based on these calorimetric results, the authors have proposed the following model: when PEG and electrolyte aqueous systems are mixed, ion and polymer interact, resulting in the release of some water molecules that were solvating the ion and polymer entities. This process occurs with the increase of the system enthalpy and entropy. Therefore, at higher temperature values, the picture arising from this model is that in which the ion + polymer interaction is favored resulting in a simultaneously increase of the salt concentration of the upper phase and, of the amount of water released from ion and polymer shells. In order to increase the configurational entropy of the system, these released water molecules should be transfered from the top phase to the bottom phase, causing an increment in the difference of water content between them (Table 1 and Table 2). This spontaneous water transference occurs because the bottom phase has a higher numeric molecular density ${ }^{32}$. As a consequence, both effects result in an increase of the STL values, since the water transference promotes the increase of the polymer concentration in the upper phase and the decrease of the salt concentration in the bottom phase. So, as higher is the ion + polymer interaction, higher will be the increase of the STL.

As already expected, ion + polymer interactions affected the binodal curve. Figure 3 exemplifies the effect of the type of salt on the phase equilibrium. According to Silva and $\mathrm{Loh}^{31}$, the phase separation of a mixture of aqueous salt and polymer systems becomes more favorable by the addition of the electrolyte until a saturation point, after what no more entropy gain may be attained. It is important to stress that this saturation does not mean physical saturation of the binding sites around the polymer, but a significant amount of electrolyte is left in solution, without interacting with polymer, destabilizing the system and hence, leading to phase separation. Sodium citrate showed better capability to induce phase separation, when compared to potassium phosphate, for all systems studied. Thus, we may suppose that citrate + PEG binding constant is lower than phosphate + PEG binding constant. As a result, a lower concentration of citrate is bound to the polymer, leaving a large fraction of citrate in bulk solution, which reaches more easily the amount of free electrolyte necessary to cause phase separation. The weakness of citrate + PEG interaction might be attributed to the complete dissociation of the citrate $\left(\mathrm{pK}_{3}=\right.$ 6.40) at $\mathrm{pH} 7$, forming a three charged anion $\left(\mathrm{CO}^{-3}\right)$ that interacts strongly with water (ion-dipole interaction) and cationic species (ionion interaction). On the other hand, phosphate is not completely ionized $\left(\mathrm{pK}_{2}=7.20\right.$ and $\left.\mathrm{pK}_{3}=12.15\right)$ at $\mathrm{pH} 7$, producing anions $\left(\mathrm{H}_{2} \mathrm{PO}_{4}^{-}\right.$and $\mathrm{HPO}_{4}^{-2}$ ) that interact with water and cationic species more weakly when compared to citrate ${ }^{27}$.

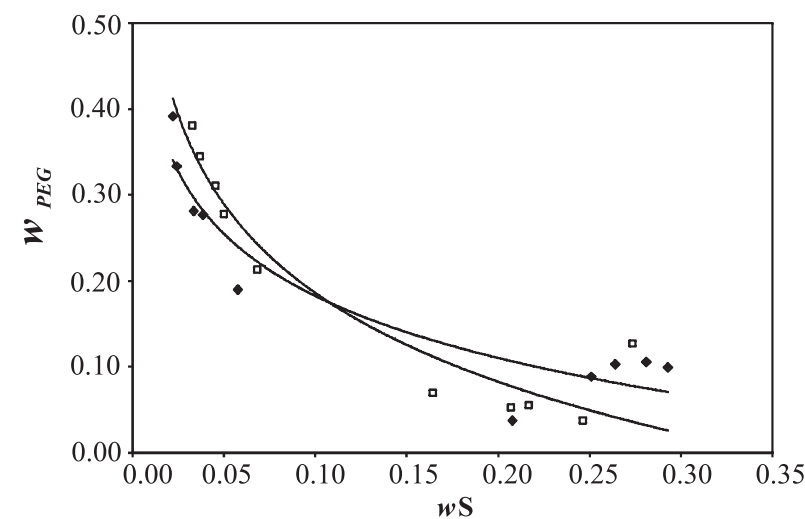

Figure 3. Influence of ionic species on the behavior of PEG $1500+$ potassium phosphate $(\square)$ and PEG $1500+$ sodium citrate $(\bullet)$ ATPS, at $298.15 \mathrm{~K}$; (一) binodal curve
The result found for PEG 1500 + potassium phosphate system A was additionally compared to the result obtained by Carvalho et al..$^{28}$ for PEG 4000 + potassium phosphate ATPS, with the purpose of evaluate the influence of the polymer molar mass on the phase equilibrium. As shown by Figure 4, the polymer with superior molar mass moved the binodal curve for the closest section to the chart axes and increased the biphasic area. Such a behavior may be explained by the difference between the molecular sizes of the polymers $^{33}$. It is well known that a increase in the polymerization degree contributes to a decrease in the entropy of mixing, for the reason that a smaller molecule have a greater number of distinguishable ways in which the molecules may be arranged in the mixture $^{34}$. In essence, PEG 4000 is capable to promote phase separation more efficiently than PEG 1500 , since its ability to increase the entropy of the systems is lower when compared to PEG 1500.

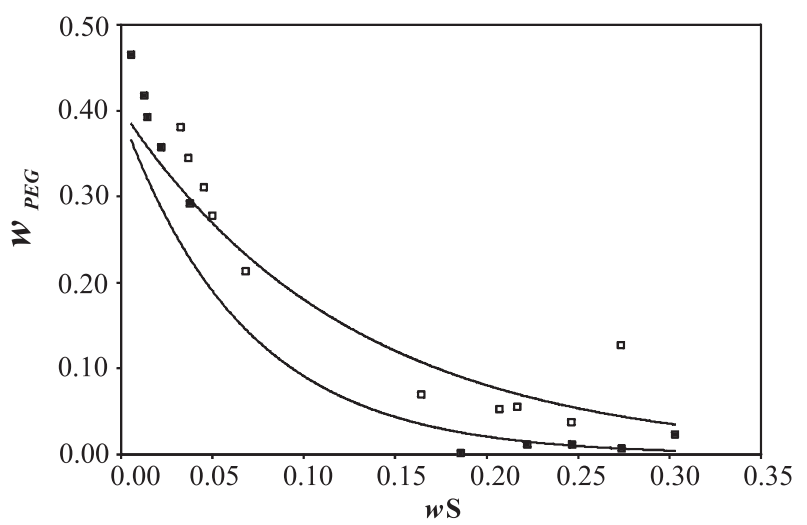

Figure 4. Influence of polymer molar mass on the behavior of PEG $1500+$ potassium phosphate $(\square)$ (this work) and PEG $4000+$ potassium phosphate (ם) (Carvalho et al. ${ }^{28}$ ) ATPS, at $298.15 \mathrm{~K}$; (一) binodal curve

\section{CONCLUSIONS}

In this work, phase equilibrium data for PEG $1500+$ potassium phosphate, from (278.15 to 318.15 ) K, and PEG 1500 + sodium citrate, from (278.15 to 298.15 ) K, were measured. The effect of the type of salt and temperature on the behavior of the ATPS was also analyzed. As sodium citrate has a weakness interaction with the ethylene glycol segments of the PEG, it is more capable to induce phase separation than potassium phosphate. On the other hand, due to the phosphate + PEG stronger binding constant, the rise of the temperature increased more the STL of the ATPS composed of potassium phosphate, when compared to those formed by sodium citrate.

\section{ACKNOWLEDGMENT}

The authors wish to knowledge the National Counsel of Technological and Scientific Development (CNPq) and the Foundation to Research Support of the Minas Gerais State (FAPEMIG) for the financial support.

\section{REFERENCES}

1. da Silva, L. H. M.; Loh, W.; Quim. Nova 2006, 29, 1345.

2. Du, Z.; Yu, Y. L.; Wang, J. H.; Chem. - - Euro. J. 2007, 13, 2130.

3. Asenjo, J. A.; Separation Processes in Biotechnology, Marcel Dekker, Inc.: New York, 1990.

4. Gunduz, U.; Korkmaz, K.; J. Chromatogr., B: Anal. Technol. Biomed. Life Sci. 2000, 743, 255. 
5. Zhi, W. B.; Deng, Q. Y.;. J. Chromatogr., A 2006, 1116, 149.

6. Queiroz, S. C. N.; Collins, C.H.; Jardim, I. C. S. F.; Quim. Nova 2001, 24, 68

7. Benjakul, S.; Klomklao, S.; Visessanguan, W.; Simpson, B. K.; Kishimura, H.; Process Biochem. (Amsterdam, Neth.) 2005, 40, 3061.

8. Chiang, B. H.; Su, C.; Process Biochem. (Amsterdam, Neth.) 2006, 41, 257.

9. Kuboi, R.; Umakoshi, H.; Solvent Extr. Res. Dev., Jpn. 2006, 13, 9

10. da Silva, M. do C. H.; da Silva, L. H. M.; Paggioli, F. J.; Coimbra, J. S. R.; Minim, L. A.; Quim. Nova 2006, 29, 1332.

11. Giraldo-Zuniga, A. D.; Coimbra, J. S. R.; Arquete, D. A.; Minim, L. A.; Silva, L. H. M.; Maffia, M. C.; J. Chem. Eng. Data 2006, 51, 1144.

12. Deng, F. Z.; Guo, D. F.; Wang, H. R.; Spectroscopy Spectral Anal. 2007, 27, 329.

13. Heipieper, H.; Neumann, G.; Cornelissen, S.; Meinhardt, F.; Appl. Microbiol. Biotechnol. 2007, 74, 961.

14. Lima, A. S.; Monte Alegre, R.; Meirelles, A. J. A.; Carbohydr. Polym. 2002, $50,63$.

15. Shang, Q. K.; Li, W.; Jia, Q.; Li, D. Q.; Fluid Phase Equilib. 2004, 219 , 195.

16. Pico, G.; Spelzini, D.; Farruggia, B.; J. Chromatogr., B: Anal. Technol. Biomed. Life Sci. 2005, 821, 60.

17. Lei, X.; Diamond, A. D.; Hsu, J. T.; J. Chem. Eng. Data 1990, 35, 420.

18. Voros, N.; Proust, P.; Fredenslund, A.; Fluid Phase Equilib. 1993, 90, 333

19. Grossmann, C.; Tintinger, R.; Zhu, J.; Maurer, G.; Phys. Chem. 1995, 99, 700
20. Mishima, K.; Nakatani, K.; Nomiyama, T.; Matsuyama, K.; Nagatani, M.; Nishikawa, H.; Fluid Phase Equilib. 1995, 107, 269.

21. Silva, L. H. M.; Coimbra, J. S. R.; Meirelles, A. J. A.; J. Chem. Eng. Data 1997, 42, 398.

22. Hatti-Kaul, R.; Mol. Biotechnol. 2001, 19, 269.

23. Silva, L. H. M.; Meirelles, A. J. A.; J. Chem. Eng. Data 2001, 46, 251.

24. Zafarani-Moattar, M. T.; Sadeghi, R.; Fluid Phase Equilib. 2001, 181, 95.

25. Zafarani-Moattar, M. T.; Sadeghi, R.; Hamidi, A. A.; Fluid Phase Equilib. 2004, 219, 149.

26. Murugesan, T.; Perumalsamy, M.; J. Chem. Eng. Data 2005, 50, 1392.

27. Tubío, G.; Pellegrini, L.; Nerli, B.; Pico, G.; J. Chem. Eng. Data 2006, 51, 209.

28. Carvalho, C. P.; Coimbra, J. S. R.; Costa, I. A. F.; Minim, L. A.; Silva, L. H. M.; Maffia, M. C.; J. Chem. Eng. Data 2007, 52, 351.

29. Pico, G.; Bassani, G.; Farruggia, B.; Nerli, B.; Int. J. Biol. Macromol. 2007, 40, 268.

30. Sadeghi, R.; Chem. Eng. Sci. 2006, 61, 7786.

31. Silva, L. H. M.; Loh, W.; J. Phys. Chem. B 2000, 104, 10069.

32. Silva, L. H. M.; Silva, M. C. H.; Aquino, R. A. N.; Francisco, K. R.; Cardoso, M. V. C.; Minim, L. A.; Coimbra, J. S. R.; J. Phys. Chem. B 2006, 110, 23540 .

33. Dallora, N. L. P.; Klemz, J. G. D.; Pessoa, P. D.; Biochem. Eng. J. 2007, 34, 92 .

34. Diamond, A. D.; Hsu, J. T.; Adv. Biochem. Eng. 1992, 47, 89. 